University of Washington Tacoma

UW Tacoma Digital Commons

Social Work \& Criminal Justice Publications

Social Work \& Criminal Justice

7-1-2010

\title{
Frontline Worker Responses To Domestic Violence Disclosure In Public Welfare Offices
}

Taryn Lindhorst

Erin A. Casey

University of Washington Tacoma, ercasey@uw.edu

Marcia Meyers

Follow this and additional works at: https://digitalcommons.tacoma.uw.edu/socialwork_pub Part of the Social Work Commons

\section{Recommended Citation}

Lindhorst, Taryn; Casey, Erin A.; and Meyers, Marcia, "Frontline Worker Responses To Domestic Violence Disclosure In Public Welfare Offices" (2010). Social Work \& Criminal Justice Publications. 64.

https://digitalcommons.tacoma.uw.edu/socialwork_pub/64 
Frontline Worker Responses to Domestic Violence Disclosure in Public Welfare Offices

Corresponding author:

Taryn Lindhorst, PhD, LCSW

Associate Professor

University of Washington

School of Social Work

$410115^{\text {th }}$ Ave NE

Seattle, WA 98155

206-616-2152

tarynlin@u.washington.edu

Erin Casey, $\mathrm{PhD}$

Assistant Professor

University of Washington, Tacoma

Social Work Program, Box 358425

1900 Commerce St., Office WCG402

Tacoma, WA 98402-5825

(253) 692-4524

ercasey@u.washington.edu

Marcia Meyers, $\mathrm{PhD}$

Professor

University of Washington

School of Social Work

$410115^{\text {th }}$ Ave NE

Seattle, WA 98155

206-616-4409

mkm36@u.washington.edu

Submission date: January 12, 2009 
Published in Social Work, 55, 235-243 - 2

Frontline Worker Responses to Domestic Violence Disclosure in Public Welfare Offices 


\begin{abstract}
Although substantial numbers of women seeking Temporary Assistance to Needy Families (TANF) report recent domestic violence, few receive mandated services through the Family Violence Option (FVO). This study used transcripts of interviews between welfare caseworkers and their clients to : 1) identify and classify the responses made by workers to client disclosures of abuse and 2) assess the match or mismatch of these responses to FVO policy requirements. Only 22 of 782 client encounters involved the disclosure of abuse to the welfare caseworker. A typology of worker responses was created, from least to most engaged. This typology shows that only half of those who disclosed abuse received some sort of assistance from the welfare worker, despite policy mandates that clients receive information on TANF waivers and community resources. This study suggests that problems with implementation of the FVO reflect a systemic reluctance to address issues of violence with women in the TANF system.
\end{abstract}

Keywords: domestic violence, TANF, poverty, frontline workers, qualitative research 
Frontline Worker Responses to Domestic Violence Disclosure in

Public Welfare Offices

The 1996 Federal Personal Responsibility and Work Opportunities Reconciliation Act ((PRWORA; U. S. Public Law 104-193, 1996) resulted in substantial changes for victims of domestic violence, while drastically altering the structure and requirements of the public welfare program for poor mothers. PRWORA changed Aid to Families with Dependent Children, an open-ended entitlement program to a time-limited, provisional work-oriented system entitled Temporary Aid to Needy Families (TANF). This transformation incorporated an over-riding emphasis on prompt integration of recipients into the work force through requirements that TANF clients be engaged in work-related activities such as job readiness training, community internships and job seeking. Under PRWORA, failure to meet these program requirements results in financial sanctions or even termination of benefit eligibility.

In recognition of the potential threats to women's safety that could be created by new welfare program requirements, Senators Patty Murray and Paul Wellstone proposed the Family Violence Option (FVO; 42 U.S.C. 602 (a) [7]) as an amendment to PRWORA. A majority of states now participate in this policy (Government Accountability Office, 2005), and by doing so, agree to screen all welfare applicants for domestic violence. If a woman discloses victimization, the welfare office is required to provide information about available community resources, and waivers to TANF rules such as work requirements, child support enforcement, and time limits if such requirements pose a danger to an abused recipient, or if domestic violence hampers an applicant's ability to comply with these program obligations.

Unfortunately, recent literature suggests that the implementation of the FVO has fallen far short of its original intent and purpose (Levin, 2001; Lindhorst \& Padgett, 2005). Although 
up to $65 \%$ of welfare recipients report some experience of victimization by an intimate partner during their lifetime and one quarter report current abuse (see Tolman \& Raphael, 2001 for a review of studies), a very small number ultimately receive FVO-related waivers or referrals. No mandate exists under current legislation to track use of the FVO in welfare systems, and only a handful of studies are available regarding implementation. The findings from these reports suggest that, at most, three percent of welfare applicants receive waivers of TANF rules under the Family Violence Option (Hetling \& Born, 2006).

In addition to the dynamics surrounding disclosure for women experiencing abuse, theories regarding low rates of FVO waiver referrals point to the potential role played by frontline workers charged with implementation of the policy. Few studies are yet available that assess the ways in which welfare workers discuss the FVO with clients who have disclosed that they are experiencing domestic violence. This research seeks to address this gap by examining transactions between welfare caseworkers and clients who have reported intimate partner abuse. More specifically, we seek to: 1) identify and classify the responses made by workers to client disclosures of abuse and 2) assess the match or mismatch of these responses to FVO policy requirements.

\section{The Role of Frontline Workers in Responding to Domestic Violence}

Welfare caseworkers express ambivalence and anxiety regarding the issue of domestic violence and their role in addressing it (Hagen \& Owens-Manley, 2002), while simultaneously facing institutional pressures that provide incentives and accountability for case closure, rather than services to survivors (Lindhorst \& Padgett, 2005). In these studies, workers described individualized belief systems about which domestic violence situations were "legitimate," and what kinds of battered women were eligible for waivers under the Family Violence Option. 
Some workers believed that women must demonstrate certain characteristics - such as having already left an abusive partner - before they would be eligible for assistance under the FVO, even though these requirements are not mandated by policy and are counter to research understandings about the dynamics of abuse (Campbell et al., 2003). Thus, individual workers' constructions of "legitimate" domestic violence may impact their willingness to share information about or grant work requirement, child support enforcement or other types of FVO waivers.

One consequence of these conflicting institutional and personal responses to domestic violence in welfare settings is an inconsistent implementation of screening for abuse, as mandated by the FVO. In a previous analysis of the data used in the research presented here, we found that only 9.3 percent of welfare application and recertification interviews included any worker-initiated screening for domestic violence, despite the FVO mandate for universal screening (Lindhorst, Meyers \& Casey, 2008). These highly scripted interviews usually ignored the issue of domestic violence, or, in a handful of cases, asked about abuse in counterproductive ways that were unlikely to produce disclosure on the part of the woman.

What remained unclear after this study, and has not yet been addressed in the literature, are the kinds of conversations that occur between frontline workers and clients following the disclosure of domestic violence. Little is known about how workers respond to a report of abuse by women seeking TANF, and how this might contribute to offering or withholding waivers and referrals. For instance, frontline welfare caseworkers may inconsistently employ interpersonal strategies that would successfully elicit domestic violence-related information from clients, such that when a client says she is experiencing abuse, the worker may not obtain sufficient information to assess whether applicants to meet the threshold of waiver eligibility. Ideally, 
caseworkers would adequately assesses the client's situation, support the client in her disclosure of abuse, and plan with the woman which services would enhance her safety and ability to address the domestic violence and her TANF-related requirements (Lindhorst, Nurius \& Macy, 2005).

To accomplish these goals, workers must recognize disclosures, and then respond in a manner that facilitates gathering additional information through appropriate assessment techniques. Survivors desire the expression of empathy and respectful, supportive responses from workers (Feder, Hutson, Ramsay \& Taket, 2006). Abused women also indicate that they need information about options and resources that will help them to achieve safety (Dienemann, Glass \& Hyman, 2005). It may be that frontline welfare workers' immediate responses to disclosures of domestic violence do not always embody these qualities, and therefore discourage women from sharing enough additional information to trigger waiver eligibility.

\section{METHOD}

Observational data for this study consisted of 782 transcribed interviews between welfare caseworkers and female clients seeking services at public welfare agencies which were originally collected as part of the Frontline Management and Practice Study conducted by the Rockefeller Institute of Government (see Meyers, Riccucci \& Lurie, 2001 for further description of the study). Data were collected from November 1999 to August 2000 at eleven sites (both rural and urban) in four states, Georgia, Michigan, New York and Texas.

Encounters between clients and workers were observed in both welfare and employment services offices and included a range of purposes such as application for TANF, arranging child care services, development of employment plans and discussion of sanctions. Prior to each encounter, informed consent was obtained for observation from the client who would be 
observed; refusals by either staff or clients were minimal. Research assistants tape recorded and transcribed data from the encounters in Texas, Michigan, and one New York agency. In Georgia and the remaining agencies in New York, permission was not given to tape record encounters. In these sites, research assistants were instructed to record verbatim 25 topics of conversation and activities that were of particular interest, including domestic violence.

During this time period, states' monthly benefits under the TANF program varied from \$201 per month for a family of 3 in Texas to \$577 in New York. Each state had adopted a "work first" approach for TANF intake that encouraged or required individuals to seek employment as a condition of their TANF application. Georgia, New York and Texas formally adopted the FVO by 1998 (U.S. Department of Health \& Human Services [U.S. DHHS], 1999), and Michigan adopted policies that were similar to the FVO (Saunders, Holter, Pahl, Tolman \& Kenna, 2005). Each state implemented the FVO at least one year prior to the beginning of data collection. All four states agreed to provide the core components of the FVO, namely, to screen applicants for domestic violence, refer identified victims to community services, and offer waivers to TANF program requirements if these would improve the woman's safety (U.S. DHHS, 1999).

\section{Data Analysis}

In the first step of the analysis, the authors read the transcripts several times in order to identify important aspects of the encounters. Each client/worker interaction was coded using the qualitative software program ATLAS.ti (Muhr, 2005). Discussions related to domestic violence were coded in the following fashion. First, all 782 client-worker interviews were read and coded as "client disclosed domestic violence" if the client indicated that she had been abused, or sought services for domestic violence from the worker or other community providers. This process identified 22 encounters in which the client identified as a victim of domestic violence. Next the 
first two authors created a matrix in which each of these 22 cases was coded for the type of interview (application, orientation meeting, etc.), descriptive information on the client where available, and recency of domestic violence. Each case was further coded for whether the frontline worker exhibited two behaviors deemed critical from literature review, namely asking for further information about the woman's current situation, and providing emotional support; and two policy-mandated behaviors, discussing FVO waiver options (i.e., in regards to work requirements, child support, time limits or sanctioning practices) and providing information on domestic violence-related community services. Using thematic qualitative analysis (Sandelowski, 2000), worker behaviors which emerged from the data were ordered to create a typology that reflected a continuum of engagement between frontline workers and clients, ranging from counterproductive behaviors to more neutral and supportive behaviors. Two counterproductive behaviors emerged from the data: not acknowledging the domestic violence disclosure and workers dissuading clients from applying for the FVO. Providing referrals was identified as a more neutral behavior because these referrals were generally not accompanied by any other helpful behavior. Based on both within-case and across-case analyses (Ayres, Kavanaugh \& Knafl, 2003), we classified each interview into one of the categories of the typology (see Figure 1 for category labels and numbers).

\section{RESULTS}

Across the 782 interviews, 22 clients disclosed some personal experience with domestic violence. Thirteen of the clients were African American women, four were white, two Hispanic, and in three cases, the racial background of the woman was not recorded. As a context for understanding the response of workers to domestic violence disclosure, these encounters had certain important characteristics. First, 14 of these encounters were the first meeting between an 
individual worker and client, in which the client was applying for TANF. As a result, in the majority of the encounters, the worker did not know about the domestic violence prior to the interview. Application interviews were highly routinized and scripted by program procedures, e.g. collecting information to determine TANF eligibility or providing clients with information about program rules and regulations. Despite this routinization, in half of the encounters, clients spontaneously reported domestic violence without being asked about this by the worker. These encounters were also noteworthy in their lack of attention paid to discussing confidentiality (mentioned in only one encounter), an important precondition for disclosure of sensitive information, and a specific requirement under the FVO.

While details of the domestic violence experience were often not shared between the worker and client, it was possible to ascertain how recently the domestic violence occurred. In all but two cases, the domestic violence was within the past year; in the two older cases, one woman reported that her partner had been sent to prison within the previous year after he tried to kill her, the remaining woman reported domestic violence that had occurred three years prior. In six cases, domestic violence was stated as the reason for the TANF application. As an example, one woman, responding to a question from the worker about why she was applying for assistance replied, "My boyfriend attempted to kill me. I moved here to get away from him." (NY715 designates state and transcript number). Four women were currently living with their children in domestic violence or homeless shelters at the time of their encounter with the TANF worker. Welfare office workers inconsistently offered information about community services or TANF waivers as mandated by the FVO in response to disclosures of domestic violence.

Overall, about half of the clients disclosing domestic violence received some tangible resource from their caseworker, such as information about possible waivers or a referral to an in-house 
domestic violence or child support case specialist; half received no referrals or resource information from the worker. Two encounters involved actively requesting that the worker see domestic violence as a central feature in the client's welfare-related issues. In both these cases, clients were accompanied at the interview by a domestic violence advocate or family member.

\section{<insert Figure 1 about here>}

\section{Typology of Worker Responses to Domestic Violence Disclosure}

After coding each case for the worker behaviors evident, a mutually exclusive categorization of each encounter was made resulting in the typology displayed in Figure 1. Evidence from the transcripts is presented next to describe each behavior.

\section{“As If It Weren't Said”: No/Minimal Acknowledgment of Domestic Violence Disclosure}

In these five encounters, workers either did not acknowledge the disclosure of violence, or minimally indicated that they heard the revelation of abuse. A common theme among these interactions was that the disclosure of violence came at a time when the worker was focused on a concrete task such as gathering information to pursue child support or to determine eligibility. Raising the topic of domestic violence may have been perceived by the worker as irrelevant to the immediate discussion. Although some of these cases may ultimately involve referrals to domestic violence-related in-house or community services outside of the recorded interview, the worker responses are devoid of any of the four elements of a desirable reaction to domestic violence disclosures. In one encounter, the worker assisted the client with tangible, welfarerelated needs created by the client's experience of domestic violence, such as replacing a stolen identification card, but did not acknowledge or assess the issue of the abuse itself. Most commonly, however, workers in this category reacted to the disclosure by simply continuing the line of questioning they had been pursuing, as in the following example: 
Worker (W): And do you have the sheet that I gave you to fill out on the absent father?

Client (C): Mm, yes...

W: And does he have a Social Security number or.....[100]

C: Huh-uh.

W: None, O.K. What's the last known address for him?

C: Mm, I don't know. [W asks several more questions like this.]

W: O.K. And when did he leave the home, approximate date?

C: Mmm... well, he came one New Year's from [city]; that's when the police picked him up. He tried to kill me.

W: O.K.

C: So it's been a year.

W: Has he written [child] since then?

C: No, huh-uh, no.

W: Was he providing child support before that time?

C: No.

$\mathrm{W}$ : So is, is he abusive?

C: Mm-hmm.

W: OK. And do you know two people that might be able to locate him, his mother, father, sisters, brothers or friends or anybody? (TX222)

In the preceding excerpt, the client discloses extreme past violence in the context of providing the worker with child support enforcement information. Although the worker seems to hear that the client's former partner is abusive, no additional assessment, nor service provision 
around the violence occurs, and the client is ultimately denied her request for emergency assistance. Seeming not to view the disclosure as relevant to the issue of child support, the worker continues to pursue avenues to find the father despite the threat posed by a former partner who attempted to kill the client.

"Putting the Genie Back in the Bottle": Worker Dissuades use of the FVO

In two encounters, the worker acknowledges the disclosure of abuse, mentions FVO waiver services, but then dissuades the client from receiving help through the FVO. In the following example of a dissuading response, the worker frames domestic violence at the outset of the conversation in the most extreme terms possible.

W: Okay... When you sign this one, what's you're telling the Attorney General's Office, don't go after him [the father]. And several reasons why we will allow you to sign it, is, one, he's already paying child support; two, you in an abuse relationship, whereas you feel that your life is threatened. He's threatening that if you go to the Attorney General's Office, he will beat you up or he will kill you or he'll come and kidnap the kids or whatever. And then what we do, is we allow you to sign this form and then when the Attorney General's Office get in touch with you, then you go into more detail, as to why.

C: Uh huh.

W: You know that's why I was asking you that.

C: Yeah.

W: But if you're not in that kind of relationship, because you have had two children from him, you do need to try to have them try to help you get child support. 
C: Yeah.

W: But you're not in that kind of situation, right?

C: No (TX630)

In this example, the client has recently separated from her partner, and has previously disclosed to the worker that her partner is harassing her, following her in a car, and coming to her worksite to pursue her. After defining domestic violence as life threatening or potentially resulting in kidnapping of the children, the worker uses a rhetorical strategy of twice telling the client that she is not having this experience. Previous research has identified the post-separation period as one of elevated risk of violence for women (Campbell et al, 2007). Without further discussion with the client, it is not possible to determine whether her current situation may be life threatening. Perhaps because of the way the worker defines domestic violence and discusses the client's situation, the client does not label her own experience as abuse (her experience is minimized) and no further assessment or waiver eligibility discussion occurs.

\section{"Referring It On"}

Three encounters can be characterized as referral responses. In each of these cases, the immediate response of the worker to disclosures of domestic violence is to refer the client to an in-house domestic violence or child support enforcement specialist without any further exploration or acknowledgement of the abuse. An example of this type of response can be found in the following excerpt:

W: Why are you here?

C: Back in March my boyfriend attempted to kill me. I moved here to get away from him.

$\mathrm{W}$ : Does he know you live here? 
C: No.

W: I'll refer you to a domestic violence worker. Where are you working? (NY715)

In this example, the client has disclosed severe violence, with unclear on-going implications for the woman's safety, mental health status or ability to work. Here, the welfare worker misses an opportunity to offer an affirming response, or to do any additional assessment. Although organizational protocol may be to refer clients who have disclosed domestic violence to an in-house specialist, the lack of an immediate, affirming response may discourage clients from seeking additional support around their experiences of abuse. Further, the compartmentalized nature of the welfare office may mean that a survivor of domestic violence has to disclose multiple times or to employees who do not view responding to disclosures as within their role. All of this is counter to available evidence about what constitutes an effective, supportive response to a disclosure that might allow clients to feel safe enough to provide the information that the worker needs to grant FVO waivers.

"Trying to Help"

In nine encounters, workers exhibited at least one of the these responses to the disclosure of domestic violence: providing client-specific information about the FVO waiver (9 encounters); asking further questions to assess the domestic violence situation ( 9 encounters), and providing emotional support (6 encounters). These behaviors were demonstrated roughly equally, regardless of whether the worker knew of the domestic violence prior to the interview; the only exception was that workers who didn't know about the abuse prior to the interview asked more follow up questions. We provide brief examples of each of these behaviors below. Providing Client Specific Information about the FVO: In order for clients to use the services available under the FVO, they have to know those services are available, relevant to 
them, and that they would not be penalized for accessing them. No worker provided information about all of the waivers available under the FVO. A waiver of pursuit of child support was most frequently discussed, with work deferrals as the second most likely topic. Workers also told clients that a sanction could be reversed, or, more generically, that they could be "exempt from requirements," but none of the workers who provided information about the FVO discussed the availability of a waiver for time limits in the client's case. Each worker appeared to come to a conclusion about what would be the most appropriate waiver for each individual client, and offered only this service. For instance, in the following encounter, the worker discusses opting out of child support requirements, but does not mention that the client can also be deferred from TANF work requirements.

$\mathrm{W}$ : OK, the reason I ask you is because when you apply for TANF, we report you to child support recovery - he might could find you. If that's gonna be a problem, let us know. [Later] This [form] is about child support recovery ... Since you've received assistance before, you know about this. But if you get new information on the fathers, you need to share it. The exception is "good cause" - like we talked about earlier with domestic violence.

In this example, the worker explains the risk the client might face if she pursues child support enforcement - her abusive partner might find her. The worker also tries to help the client understand the jargon of the TANF department by tying their earlier discussion about domestic violence to the term "good cause," in essence, teaching the client the words that are used in the TANF office to talk about domestic violence waivers.

Asking Follow Up Questions: In contrast to the ten cases in which the worker asked for no further information on the client's domestic violence situation, helpful workers tended to ask 
questions to assess the seriousness of the domestic violence and its effect for the woman. For example, in the following interaction, the worker asks four questions to assess the level of threat that the client feels in response to the abuse she has disclosed.

W: Are you threatened by him?

C: Not threatened.

W: He know where you live?

C: No, we haven't had any contact.

W: If he found out where you live, would it be a problem?

C: No, it's nothing like that. We just [pause]

W: Just some bickering. OK. [pause] So he slap you around a bit, when y'all were fighting?

C: Not all the time, every 2-3 weeks. (GA079)

This example also illustrates a dynamic in domestic violence situations, namely, that women may experience physical harm, but by complicated reasoning, they do not equate this harm with abuse. In this case, the fact that physical hitting did not occur "all the time" meant that the client saw her situation as not being threatening. However, the client also states that she has not had any contact with her former partner, indicating a degree of concern about contact with him. Further assessment and information about domestic violence might help this client to evaluate the level of risk in her situation.

Emotional Support: Less frequently, workers offered some form of emotional support, or reflective statements that communicated their concern, or their regard for the client. The following excerpt is an example of a supportive response in which the worker attends to the 
emotional content of the client's expression, and reaffirms that she is not to blame for the violence.

C: The last time he went, they gave him a year probation, and they took like a violence class. And he told me "I'm gonna kill you bitch, I'm gonna kill you bitch. I went to jail bitch, I'm going to kill you bitch. You know it is all your fault." I said it was my fault, you know. For a long time I did. A long time. W: Well, he made you think it was your fault because he kept saying it. C: Yeah.

W: It's not your fault. (MI091).

\section{"Putting It All Together"}

In contrast to helpful responses, in which a worker would exhibit one or maybe two of the helpful behaviors described above, three workers were able to use all of these behaviors in the encounter with the domestic violence survivor. Additionally, these three cases were the only ones in which the workers provided information to the clients about external community-based resources, such as domestic violence shelters, crisis lines, or daycare options while at the domestic violence shelter. In these three encounters, workers took time to discuss the violence, asking follow-up questions to assess the level of violence, offering non-judgmental and empathetic statements to the client, explicitly letting the client know that the violence was not her fault, engaging in problem-solving related to the abuse, and explaining waivers that would be available to the client under the FVO. Although the numbers are too low to draw firm conclusions, it is interesting to note that each of these three effective encounters occurred in Michigan (at different locations), a state which has invested in domestic violence training for its welfare workers (Saunders et al., 2005). 
In two of these encounters, the client's domestic violence history was known prior to the interview or was the purpose of convening the meeting; in one case, a spontaneous disclosure of abuse resulted in a series of supportive responses from the worker. In this encounter (excerpted below), the worker sets aside a particular time to assess the client's connection with community services, and to evaluate whether other welfare services or waivers might be necessary.

W: I wanted the children to leave while we talked about domestic violence. Um. I don't know, you said you had dialed the number [for the DV agency]. I have like five numbers and maybe one of them can help, even like a crisis number where they'll help with housing and everything. But you might want to give them all a try.

C: They gonna want me to tell them where he live and all that stuff?

W: You know, to tell you the honest truth, I don't know for sure what they ask. But some places, I don't think require that, they're just like a safe haven, in the meantime. And it doesn't matter if you have one child or twenty kids or fifty kids. They just want a safe haven for you... Also, have you reported, you have a police report [about] the domestic violence?

C: Yeah, but then when the police came, and when the police left he still beat me up. It doesn't make no difference.

W: But you know it makes a difference with, with us. You know how you been sanctioned and your case is threatening to close, you can bring that police report in to me and you'll be exempt. You wouldn't have to do the Work First, you wouldn't be sanctioned and all this other. (MI077)

In this interview, the worker recognizes her responsibility to create a safe and confidential environment for discussing domestic violence (by asking the children to leave), provides 
information on community resources (numbers to a crisis line and community agencies), tells the client that disclosing the violence "makes a difference," and informs her that she is eligible for a waiver from TANF rules that might help her avoid sanction or the closure of her case. This worker has demonstrated through this interaction her empathy for the client, her respect for the client's confidentiality needs, and expressed her desire to help the client.

\section{DISCUSSION}

The study presented here was conducted at eleven different sites with dozens of welfare caseworkers and hundreds of clients; it represents a naturalistic inquiry into the question of how domestic violence is addressed in encounters between welfare workers and their clients. Despite the fact that other research has found that as many as 25 percent of TANF recipients report domestic violence within the past year (Tolman \& Raphael, 2001), only three percent of the clients in this study disclosed abuse to their welfare caseworker. Only about half of those who disclosed abuse received some sort of assistance from the welfare worker, a disappointing indication that implementation of the FVO continues to be sporadic at best. However, since client disclosures happened in roughly the same number across four states who had implemented the FVO (or similar policies), this suggests that problems with implementation of the FVO are not confined to the level of individual worker behavior, but rather reflect a systemic reluctance to address issues of violence with women in the TANF system.

We found evidence in these encounters that workers do not consistently use interpersonal communication strategies that are likely to support clients in disclosing enough information about their situations to trigger eligibility for FVO services. In this sample of encounters between workers and clients who disclosed domestic violence, only three workers asked appropriate assessment questions, offered support related to the disclosure of abuse, engaged in information 
sharing about the FVO and community resources, and worked with the woman to determine the safest strategy for her situation. In contrast, nearly half of workers used no helpful strategies, ignoring disclosures of abuse, trying to talk clients out of accessing FVO services, or referring them to other workers without further engagement. Although the remainder of workers exhibited one or two helpful behaviors, these were not sufficient to adequately assess, support, share information and plan with the clients.

Workers also appeared to have internalized ideas about what constituted domestic violence, and what their role should be in addressing it. As described above, one worker defined domestic violence in its extremity, such as being beat up or having children kidnapped. This statement raises issues related to how one defines being "beat up" -- how much hitting is required before it goes beyond being "slap[ped]... around a bit" (as a worker from Georgia remarked)? Ten of the encounters described here showed workers who did not see responding to domestic violence as within their scope of work. Previous research has documented the tensions workers experience in regards to accountability for caseload reductions and efficient processing of clients (Lindhorst \& Padgett, 2005). Workers may need a range of interventions to improve their responses to battered women in the TANF system, including training on dynamics of domestic violence, appropriate assessment and response, and information about the resources available internally and within the community for domestic violence survivors. Although training is a necessary component of helping workers to respond to abuse survivors, without a systemic commitment to embracing the responsibility of the public welfare system to these women, training will be an insufficient response. If workers continue to have their performance assessed solely on the basis of moving clients off TANF rolls, there will continue to be little institutional incentive to identify women with domestic violence concerns. 


\section{Limitations}

This research is cross-sectional, providing a snapshot of processes related to disclosures of domestic violence early in the implementation of the FVO. States, offices and workers may have subsequently evolved and refined their service delivery efforts. Because only the encounter was observed and no further information was available about the client, we could not determine whether cases involving a discussion of a work or child support-related waiver resulted in the eventual granting of the waiver; or if in subsequent conversations, FVO or community resource information was provided. The transcripts may not always note important nonverbal communication occurring between worker and client that might be relevant to understanding worker and client responses, and in Georgia and one office in New York, the written transcripts may not capture all relevant dialogue. While these data provide a compelling picture of implementation activities in 11 welfare offices, the states and offices participating in this study were not randomly chosen, so generalizability of these findings to other states may be limited. Conclusion

Welfare offices will continue to see battered women with children who have few other alternatives for obtaining financial support to escape abusive relationships. An opportunity for enhancing the safety of vulnerable women and their children is lost when disclosure of domestic violence does not result in further assessment or the provision of needed services. These data suggest that much work continues to be needed to assist TANF workers to respond appropriately to disclosures of abuse, and to help battered women who enter the TANF system to advocate for the resources they need to enhance their safety. Social workers can be important allies in these efforts through their work with domestic violence survivors, their positions within state welfare systems, and their work as advocates for poor and abused women. 


\section{REFERENCES}

Ayres, L, Kavanaugh, K., \& Knafl, K.A. (2003). Within-case and across-case approaches to qualitative data analysis. Qualitative Health Research, 13, 871-883.

Campbell, J. C., Webster, D., Koziol-McLain, J., Block, C., Campbell, D., Curry, M. A., Gary, F., Glass, N., McFarlane, J., Sachs, C., Sharps, P. Ulrich, Y., Wilt, S. A., Manganello, J., Xu, X., Schollenberger, J., Frye, V., \& Laughon, K. (2003). Risk factors for femicide in abusive relationships: Results from a multisite case control study." American Journal of Public Health, 93, 7, 1089 - 1097.

Dienemann, J., Glass, N. \& Hyman, R. (2005). Survivor preferences of response to IPV disclosure. Clinical Nursing Research, 14, 215-233.

Feder, G. S., Hutson, M., Ramsay, J., \& Taket, A. R. (2006). Women exposed to intimate partner violence: Expectations and experiences when they encounter health care professionals: A meta-analysis of qualitative studies. Archives of Internal Medicine, 166, 1, 22-37.

Government Accountability Office. (2005). State approaches to screening for domestic violence could benefit from HHS Guidance. GAO-05-701. Washington, DC: Author.

Hagen, J.L. \& Owens-Manley, J. (2002) Issues in implementing TANF in New York: the perspective of frontline workers. Social Work, 47, 171-182.

Hetling, A. \& Born, C. (2006). Specialists in welfare offices: Do family violence experts matter? Administration in Social Work, 30, 4, 19 -36.

Levin, R. (2001). Less than ideal: The reality of implementing a welfare to work program for domestic violence victims and survivors in collaboration with the TANF department. Violence against Women, 7, 211-221. 
Lindhorst, T., Meyers, M., \& Casey, E. (2008). Screening for domestic violence in public welfare offices: An analysis of case manager and client interactions. Violence against Women, 14, 5, 5- 28.

Lindhorst, T., Nurius, P., \& Macy, R. (2005). Contextualized assessment with battered women: Strategic safety planning to cope with multiple harms. Journal of Social Work Education, 41 (2): 371-393.

Lindhorst, T. \& Padgett, J. (2005). Disjunctures for women and frontline workers: Implementation of the Family Violence Option. Social Service Review, 79 (3) 405-29.

Meyers, M. K., Riccucci, N. M. \& Lurie, I. (2001). Achieving goal congruence in complex environments: The case of welfare reform. Journal of Public Administration Research and Theory, 11 (2): 165-201.

Muhr, T. (2005). ATLAS.ti. Scientific Software Development GmbH, Berlin, Germany.

Saunders, D. G., Holter, M. C., Pahl, L. C., Tolman, R. M., \& Kenna, C. E. (2005). TANF workers' responses to battered women and the impact of brief worker training. Violence against Women, 11, (2): 227-254.

Sandelowski, M. (2000). Whatever happened to qualitative description? Research in Nursing and Health, 22, 334-340.

Tolman, R.M. \& Raphael, J. (2001). A review of research on welfare and domestic violence. Journal of Social Issues, 56, 655-682.

U. S. Department of Health and Human Services, Administration for Children and Families, Office of Planning, Research and Evaluation. (1999). Temporary Assistance for Needy Families (TANF): $2^{\text {nd }}$ Annual Report to Congress. [Online] Available at: http://www.acf.hhs.gov/programs/ofa/indexar.htm. 
Published in Social Work, 55, 235-243 - 22

Figure 1. Typology of Frontline Worker Responses to Domestic Violence Disclosure.

Least Engaged

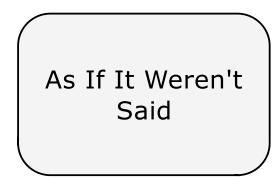

(5 encounters)

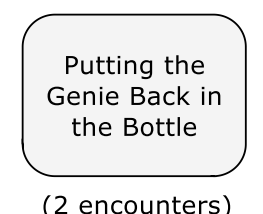

( 2 encounters)

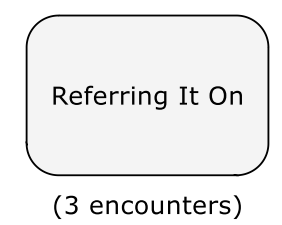

Most Engaged

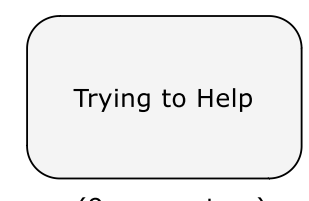

(9 encounters)
Putting It All Together

(3 encounters) 